\title{
SOROPREVALÊNCIA DE SÍFILIS EM REEDUCANDOS DO PRESÍDIO REGIONAL DE CRICIÚMA/SC E PENITENCIÁRIA FEMININA DE CRICÚMA/SC
}

DOI: http://dx.doi.org/10.18616/prat08

\begin{abstract}
Patriny Luiz Clezar UNESC - Universidade do Extremo Sul Catarinense patriny_tiny@hotmail.com

Haylla Santos de Sousa UNESC - Universidade do Extremo Sul Catarinense aideehailla@hotmail.com

Emanuel de Souza UNESC - Universidade do Extremo Sul Catarinense emanuel@unesc.net
\end{abstract}




\section{INTRODUÇÃO}

A sífilis é uma doença infecciosa crônica a qual apresenta como agente etiológico o Treponema pallidum, podendo afetar diversos sistemas e órgãos, como pele, fígado, coração e sistema nervosa central. Tornou-se conhecida na Europa, no final do século XV, e alastrou-se pelo mundo transformando-se em uma doença endêmica no século XIX (AVELEIRA, BOTTINO, 2006).

Os casos de sífilis têm aumentado ano a ano no mundo, no Brasil e em Santa Catarina. A estimativa da Organização Mundial da Saúde é que 937 (novecentos e trinta e sete) mil pessoas são infectadas a cada ano no país. Em Santa Catarina, nos últimos cinco anos (2010-2015), 15.797 (quinze mil, setecentos e noventa e sete) pessoas foram diagnosticados com sífilis adquirida. Além desses, foram 3.339 (três mil e trezentos e trinta e nove) novos casos em gestantes (notificadas separadamente) no mesmo período. Os números de sífilis congênita (transmissão da doença da mãe para o bebê) também se elevaram, passando de 76 (setenta e seis) casos em 2010 para 475 (quatrocentos e setenta e cinco) casos em 2015, acrescentou aproximadamente 5 (cinco) vezes. Em relação aos dados de 2015, foram registrados 5.706 (cinco mil e setecentos e seis) novos casos de sífilis adquirida, um crescimento de 53,5\% em comparação aos casos notificados no ano anterior no ano anterior, quando foram notificados 3.716 (três mil e setecentos e dezesseis) casos. Em relação às gestantes (notificadas separadamente), o aumento do número de novos casos foi 61\%, passando 777 (setecentos e setenta e sete) em 2014 para 1.254 (mil duzentos e cinquenta e quatro) em 2015. Já a sífilis congênita apresentou crescimento de $75 \%$, com 475 (quatrocentos e setenta e cinco) novos casos notificados em 2015 e 272 (duzentos e setenta e dois) em 2014 (SANTA CATARINA, 2017).

Verifica-se que houve um aumento da síflis no Brasil em $68,2 \% \mathrm{em}$ 2013, com aumento de 55,7 \% nos casos entre os homens e $97,7 \%$ entre as mulheres, das notificações em relação ao ano anterior (BRASIL, 2014). 
Acredita-se que ocorram anualmente 12 (doze) milhões de casos novos de sífilis na população adulta em todo o mundo, 90\% deles nos países em desenvolvimento. As estimativas apontam a sífilis congênita como responsável por mais de 500 (quinhentas) mil mortes fetais por ano no mundo (CAMPOS et al., 2010).

Destaca-se por ser uma doença cosmopolita a qual atinge todas as classes sociais. A fonte de infecção é exclusivamente humana, bem como são contagiosas as manifestações primária e secundária. Não confere imunidade, sendo, portanto, possível a reinfecção e sobreinfecções. São mais acometidos aos jovens, principalmente entre 15 (quinze) e 25 (vinte e cinco) anos de idade, eis que possuem atividade sexual mais recorrente (BELDA et al., 2009).

A sífilis é transmitida, sobretudo, por via sexual, transfusional sanguínea, verticalmente na gestação, inoculação por via indireta por meio de objetos contaminados como agulhas, em procedimentos de introdução de "piercing" e de tatuagens. Ademais, a doença tem uma evolução alternada entre períodos de atividade bem definidos com sinais clínicos, imunológicos e histopatológicos que estabelecem três formas da doença: a sífilis primária; a sífilis secundária e a sífilis terciária (AVELHEIRA, 2006).

Não existe nenhum limite estabelecido entre a sífilis primária e secundária. $\mathrm{O}$ cancro inicial pode estar presente em um terço dos pacientes com sífilis secundária. Além disso, a lesão inicial poderá ser cicatrizada entre 8 (oito) semanas antes que os sinais cutâneos surjam. Em média, após um período de latência de 6 (seis) a 8 (oito) semanas, a infecção entrará novamente em atividade (SINGH; ROMANOWSKI, 1999, AVELLEIRA; BOTTINO, 2006).

A sífilis primária é definida por uma lesão específica. O cancro duro surge no local da inoculação - 95\% dos casos na região genital - em média 3 (três) semanas após a infecção. No homem, a lesão é mais comum no sulco balanoprepucial, prepúcio e meato uretral. Na mulher, ocorrem nos pequenos lábios, parede vaginal e colo uterino (CONTRERAS et al., 2008).

A inoculação inicial do Treponema pallidum ocorre por contágio sexual por meio de lesões microscópicas ou aparentes na pele ou nas mucosas. 
A ulceração (cancro), a linfadenopatia regional e a espiroquetemia caracterizam a sífilis primária. O período de incubação da bactéria é de 9 (nove) a 90 (noventa) dias. Todavia, a úlcera desaparece em torno de 3 (três) semanas. No período entre 7 (sete) a $10(\mathrm{dez})$ dias após a infecção, ocorre a disseminação bacteriana por via linfática a partir do sítio de inoculação, do cancro, o que desencadeia uma resposta imune que é caracterizada pelo desenvolvimento da linfadenopatia regional (CARLSON et al., 2011).

A sífilis secundária é acompanhada de poliadenomegalia generalizada e possui alguns sintomas inespecíficos, tais como: mal-estar, astenia, anorexia, febre baixa, cefaleia, meningismo, artralgias, mialgias, faringite, rouquidão, hepatoesplenomea (AVELLEIRA; BOTTINO, 2006).

Após o período de 6 (seis) a 8 (oito) semanas de latência, a doença ingressa novamente em atividade. Nessa fase, o acometimento estará localizado na pele e órgãos internos, correspondendo à distribuição da bactéria Treponema pallidum pelo corpo (CONTRERAS et al., 2008).

Na sífilis terciária, os indivíduos poderão estar na fase de desenvolvimento de lesões na pele e mucosas, sistema cardiovascular e nervoso, ossos, músculos e fígado. Nessa fase, haverá ausência de grande parte de treponemas, e a formação de granulomas destrutivos (gomas). As lesões são únicas ou em pequeno número, endurecidas apresentando pequena inflamação e possui propensão à cura no centro da lesão. Pode agredir a língua com espessamento e endurecimento do órgão. Porém, a lesão não causa dor. O palato pode ser invadido por lesões gomosas e destruída a base óssea do septo nasal (AVELLEIRA; BOTTINO, 2006).

A sífilis congênita tem o Treponema pallidum presente na corrente sanguínea da gestante infectada, atravessando a barreira placentária via corrente sanguínea, atingindo o feto. Além do mais, a transmissão pode ocorrer em qualquer momento da gestação. Ou seja, quanto mais recente a infecção, mais treponemas estarão circulantes e, portanto, mais gravemente o feto será acometido (LAFOND; LUKEHART, 2006). 
A disseminação do Treponema pallidum através da placenta procede em sífilis congênita. $\mathrm{O}$ risco de contaminação fetal depende do estágio da infecção em que a mãe se encontra e também da idade gestacional em que ocorre a exposição fetal. A infecção transplacentária pode ocorrer durante as fases primária, secundária, latente precoce e latente tardia da sífilis materna.

Pelo fato de o sistema imunológico fetal ser extremamente fraco, na fase inicial da gravidez, a resposta inflamatória só se torna eficaz em torno de 18 (dezoito) a 22 (vinte e duas) semanas de gestação. Após este período surgem as manifestações da sífilis congênita. Com a presença do processo inflamatório decorrente da presença do Treponema pallidum, acaba reduzindo a passagem sanguínea para o feto, que pode estar afetando o crescimento ou mesmo causando a morte do feto. Crianças acometidas pela sífilis congênita exibem nos dois primeiros anos de vida hepatoesplenomegalia, anemia, icterícia, prurido, rinite e pseudoparalisia. Após os dois primeiros anos de vida, a criança pode apresentar manifestações neurológicas tratáveis, retardo no desenvolvimento e problemas músculo esqueléticos (BLENCOWE et al., 2011).

O diagnóstico laboratorial da sífilis e a escolha dos exames laboratoriais mais adequados deverão respeitar a fase evolutiva da doença. Na sífilis primária e em algumas lesões da fase secundária, o diagnóstico poderá ser direto, ou seja, feito pela demonstração do treponema. A utilização da sorologia poderá ser feita a partir da segunda ou terceira semana após o aparecimento do cancro, quando os anticorpos começam a ser detectados (AZULAY, 2004; SANCHEZ, 2003; ROTTA, 2005).

O diagnóstico da sífilis é fundamentado na análise das manifestações, a identificação ou demonstração do Treponema pallidum será possível nas fases em que há comparecimento de lesões, ou seja, na sífilis primária e na sífilis secundária. Provas sorológicas poderão ser utilizadas de 2 (duas) a 3 (três) semanas após o começo do cancro, quando ocorre a soroconversão, estando possível a detecção de anticorpos (GRANGE et al., 2011; TIPPLE et al., 2011). 
O diagnóstico da sífilis tem como, primeiro teste, as reações de fixação de complemento. As reações de Wassermann e Khan utilizavam material extraído de tecidos de difícil padronização e acabaram cedendo lugar aos antígenos mais purificados, como o VDRL (Venereal Disease Research Laboratory) que utiliza um antígeno composto de lecitina, colesterol e cardiolipina purificada. A cardiolipina é um elemento da membrana plasmática das células dos mamíferos liberado após dano celular e encontra-se presente também na parede do Treponema pallidum (AVELEIRA; BOTTINO, 2006).

$\mathrm{O}$ teste de VDRL encontra-se positivo entre cinco e seis semanas posteriormente a infecção. Assim sendo, pode estar negativa na sífilis primária. Na sífilis secundária apresenta sensibilidade alta, e nas formas tardias, a sensibilidade diminui. A reação não é peculiar, podendo estar positiva em outras treponematoses e em várias outras situações. Essas reações falso-positivas podem ser divididas em transitórias e persistentes. As transitórias negativam em seis meses (malária, gravidez, mononucleose infecciosa, viroses, tuberculose e outras) (AZULAY, 2004; SANCHEZ, 2003; ROTTA, 2005).

Já o teste imunocromatográfico, também conhecido como teste rápido, é útil para determinação qualitativa de anticorpos totais (IgG, IgM e IgA) anti-Treponema pallidum em amostras de soro, plasma ou sangue total. Nessa metodologia, antígenos recombinantes de Treponema pallidum estão imobilizados na região da linha teste. Quando uma amostra é adicionada, esta reage com partículas coradas conjugadas a antígenos de Treponema pallidum. Este complexo migra ao longo da tira teste e interage com os antígenos imobilizados. Se a amostra apresentar anticorpos anti-Treponema pallidum, uma banda colorida irá aparecer na região teste indicando um resultado positivo. Se a amostra não apresentar anticorpos anti-Treponema pallidum, essa banda não irá aparecer indicando um resultado negativo. (BIOCLIN; SÍFILISBIO, 2017)

Em torno de um ano de infecção, nas primeiras fases, a doença conta com grandes chances de cura com dose única de penicilina. Se for após este período de um ano, multidoses devem ser adotados para o tratamento. A penicilina interfere na síntese de peptideoglicano da parede celular do Treponema 
pallidum permitindo a entrada de água na célula bacteriana o que causa a sua lise por turgescência (AVELLEIRA; BOTTINO, 2006).

A penicilina continua sendo a alternativa para tratamento devido à sensibilidade do Treponema à droga e a rapidez da resposta com regressões das lesões primárias e secundárias com apenas uma dose. O nível terapêutico eficaz é de $0,03 \mu / \mathrm{cm}^{3}$ devendo ser mantido pelo tempo superior ao da divisão da bactéria. Para manter este nível terapêutico deve ser utilizada a penicilina benzatina. Na neurossífilis a opção é a penicilina cristalina que tem a competência de atravessar a barreira hematoencefálica. (AVELLEIRA; BOTTINO, 2006).

O sistema prisional é visto como um problema de saúde pública no mundo, visto que, nos presídios existem condições que beneficiam a propagação de doenças sexualmente transmissíveis, tendo em vista que, nestes locais nos deparamos com condições relacionadas à violência, apresenta espaço físico limitado e a saúde imprópria aos detentos (GARAYCOCHEA et al., 2013; AGNOLO et al., 2013).

A sífilis congênita é uma doença de notificação compulsória, desde 22 de dezembro de 1986, por meio da portaria n. 542 do Ministério da Saúde, juntamente com a síndrome da imunodeficiência adquirida (Aids) (Ministério da Saúde 1986). A notificação da sífilis em gestantes só se tornou obrigatória com a publicação da Portaria MS/SVS N. 33, assinada em 14 de julho de 2005. (DIRETRIZES PARA CONTROLE DE SÍFILIS CONGÊNITA, 2005)

As Doenças de Notificação Compulsória (DNC) são assim designadas por constarem na Lista de Doenças e Agravos de Notificação Compulsória, em âmbito mundial, nacional, estadual e municipal. São doenças cuja gravidade, magnitude, transcendência, capacidade de disseminação do agente causador e potencial de causar surtos e epidemias exigem medidas eficazes para sua prevenção e controle, a sífilis está na categoria de DNSC. (SILVA; OLIVEIRA, 2014).

O caso confirmado pelos gestores prisionais nos abona a informação sobre o período de incidência da doença, somente indicam a quantidade de casos que prevalecem em um momento considerado e, portanto, trata-se de prevalências (BRASIL, 2014). 
Segundo a nota informativa do governo de n. 2 - SEI $\backslash 2017$ altera os critérios para definição de casos para notificação sífilis, a situação 2 da nota, cita que é notificado em qualquer titulação, apenas ter um resultado de exame, treponêmico, ou não-treponêmico. Antes dessa nota, os profissionais da saúde, só poderiam notificar, os resultados de VDRL, que aparecessem com titulação alta. (Brasília, 2017). Além disso, é importante ressaltar que no ambiente prisional a dessemelhança dos indivíduos confinados, proporciona uma maior exposição aos riscos físicos e psicológicos (NICOLAU et al., 2012).

A saúde de um cidadão tem relação com o ambiente que vive e de outras variáveis sociais, como também, psíquicas e biológicas. Deste modo as condições que o mesmo habilita, tendo em vista a qualidade do meio, poderá interferir diretamente no seu estado de saúde. Desse modo a precariedade do ambiente prisional brasileiro, se dá, devido a superlotação, assim, definindo, muitas vezes o estado de saúde dos presidiários (COELHO; PASSOS, 2011).

\section{MÉTODOS}

Este trabalho foi encaminhado ao Comitê de Ética em Pesquisa da Universidade do Extremo Sul Catarinense reconhecido pela Comissão Nacional de Ética em Pesquisa (CONEP) / Ministério da Saúde analisou o projeto abaixo. Parecer n.: 2.563.782 e CAAE: 85658818.0.0000.0119. O estudo foi realizado no Presídio Regional de Criciúma-SC e na Penitenciária Feminina de Criciúma-SC.

Os participantes foram os reeducandos voluntários do regime fechado do Presídio Regional de Criciúma-SC e da Penitenciária Feminina de Criciúma-SC no período de abril a maio de 2018. Foram incluídos no estudo todos os indivíduos com sorologia positiva e negativa para a bactéria Treponema pallidium, com idade mínima de 18 , do sexo feminino e masculino, que se disponibilizaram a participar da pesquisa, entre 10 de abril a $15 \mathrm{de}$ maio. Foram excluídos os indivíduos que, por algum motivo, não puderam 
se fazer presente no período da coleta e também aqueles que não aceitaram participar do estudo.

Fizeram parte desse estudo 46 mulheres da Penitenciária Feminina de Criciúma-SC feminina e 85 homens do Presídio Regional de Criciúma-SC, totalizando 131 indivíduos. Primeiramente foi executado o teste rápido imunocromatográfico de sífilis nos reeducandos do Presídio Regional de Criciúma e na Penitenciária feminina de Criciúma. Os reeducandos que apresentaram positividade no teste rápido, foram confirmados com teste não treponêmico de VDRL.

Os dados foram coletados pela autora deste trabalho três vezes por semana, nas segundas-feiras, quarta-feira e quintas-feiras, no período matutino, e vespertino sob supervisão da enfermeira responsável Renata do Presídio Regional de Criciúma, e pelas enfermeiras responsáveis da Penitenciária Feminina de Criciúma, Fabiana e Sandra, durante todo o mês de coleta.

Os dados foram organizados em planilhas dos softwares Microsoft Excel versão 2013 e IBM Statistical Package for the Social Sciences (SPSS) versão 20.0 para a análise estatística. Todos os voluntários assinaram o Termo de Consentimento Livre e Esclarecido. Para a análise estatística foi elaborada uma planilha eletrônica, para organização do banco de dados a partir da coleta. As variáveis qualitativas são apresentadas em frequência absoluta e relativa. Para comparação entre grupos foi utilizado o teste de Qui-quadrado de Pearson ou teste exato de Fisher, conforme indicado. As variáveis quantitativas foram apresentadas em média \pm desvio padrão ou mediana e amplitude interquartil (AIQ), conforme indicado. Para as comparações das variáveis quantitativas entre grupos foi utilizado o teste t de Student ou U de Mann-Whitney Ranksum, precedidos de teste de Shapiro-Wilk para verificar a normalidade da distribuição dos dados. Para todas as análises estatísticas foi adotado o valor de $\mathrm{p}<0,05$ para indicar diferença estatisticamente significativa entre os grupos. 


\section{RESULTADOS}

Os testes rápidos foram executados no sistema prisional na cidade de Criciúma-SC, sendo duas unidades, a Penitenciaria Feminina e o Presídio Regional, no ano de 2018, onde foi obtido 131 voluntários. Verificou-se que a média de idade desses voluntários foi de 30,42 \pm 9,74 anos, tendo como idade mínima 18 (dezoito) anos e máxima de 55 (cinquenta e cinco) anos.

$\mathrm{O}$ teste rápido constatou 15 (quinze) voluntários positivos e 116 (cento e dezesseis) voluntários negativos. Como teste confirmatório, foi utilizado o VDRL, o qual contatou 11 (onze) voluntários positivos e 120 (cento e vinte) voluntários negativos. Destes 11 (onze) voluntários positivos, sendo que 7 (sete) eram do sexo feminino, e 4 (quatro) do sexo masculino. A média de idade dos voluntários que apresentaram sífilis positiva foi de 30,64, com desvio padrão de 10,22, e com uma média de 2,00 anos de período de reclusão. As tabelas 1 e 2 mostram as variáveis que foram analisadas no estudo e seus respectivos resultados.

Tabela 1 - Característica geral da amostra

\begin{tabular}{|c|c|}
\hline Variáveis & Média \pm desvio padrão ou $n(\%) n=131$ \\
\hline Idade (anos) & $30,42 \pm 9,74$ \\
\hline Até 30 anos & $78(59,5)$ \\
\hline Entre 30 e 45 anos & $41(31,3)$ \\
\hline \multicolumn{2}{|r|}{ Sexo } \\
\hline Masculino & $85(64,9)$ \\
\hline \multicolumn{2}{|r|}{ Estado } \\
\hline Santa Catarina & $104(79,4)$ \\
\hline Paraná & $12(9,2)$ \\
\hline Rio Grande do Sul & $9(6,9)$ \\
\hline Minas Gerais & $3(2,3)$ \\
\hline São Paulo & $1(0,8)$ \\
\hline
\end{tabular}




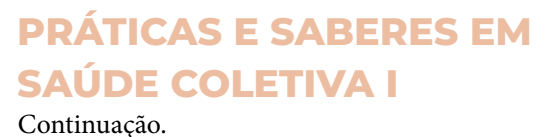

\begin{tabular}{|c|c|}
\hline Variáveis & Média \pm desvio padrão ou n (\%) $n=131$ \\
\hline Rio de janeiro & $1(0,8)$ \\
\hline \multicolumn{2}{|r|}{ Raça } \\
\hline Branco & $82(62,6)$ \\
\hline Pardo & $29(22,1)$ \\
\hline Preto & $19(14,5)$ \\
\hline \multicolumn{2}{|c|}{ Escolaridade } \\
\hline Ensino fundamental & $109(83,2)$ \\
\hline Ensino médio & $18(13,7)$ \\
\hline \multicolumn{2}{|c|}{ Estado civil } \\
\hline Solteiro (a) & $64(48,9)$ \\
\hline Casado (a) & $33(25,2)$ \\
\hline União estável & $28(21,4)$ \\
\hline Divorciado (a) & $4(3,1)$ \\
\hline Renda & $1200(950-1800)$ \\
\hline Menor que 1 salário-mínimo & $17(13,0)$ \\
\hline Entre 1 e 2 salários-mínimos & $13(9,9)$ \\
\hline Entre 2 e 3 salários-mínimos & $72(55,0)$ \\
\hline Entre 3 e 4 salários-mínimos & $27(20,6)$ \\
\hline Período preso (anos) & $1,00(0,42-2,58)^{*}$ \\
\hline \multicolumn{2}{|c|}{ AIQ= Amplitude interquartil. $\mathrm{DP}=$ desvio padrão. } \\
\hline \multicolumn{2}{|c|}{ ^Valor obtido após aplicação do teste U de Mann Whitney. } \\
\hline \multicolumn{2}{|c|}{ **Valor obtido após aplicação do teste de razão de verossimilhança. } \\
\hline \multicolumn{2}{|c|}{ 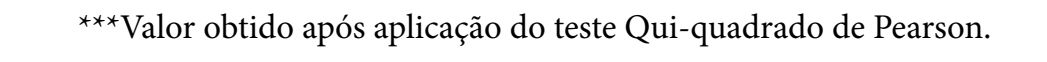 } \\
\hline
\end{tabular}

A tabela 2 demonstra informações referentes aos fatores de riscos que os reeducandos se expõem, bem como mostra as variáveis, onde se pode analisar que a maioria dos reeducandos não possui conhecimento acerca da sífilis, além de não fazerem o uso de preservativo em suas visitas íntimas. Ainda, a maior parte possui tatuagens. As titulações que mais prevaleceram 
no teste foram de $1 \backslash 2$, onde $6(54,5 \%)$ reeducandos acusaram essa titulação. A carga bacteriana mais alta que o estudo encontrou foi de $1 \backslash 32 \mathrm{em}$ apenas um reeducando.

Tabela 2 - Fatores de risco, titulações e resultados de VRDL.

\begin{tabular}{|c|c|}
\hline Variáveis & $\mathrm{n}(\%) \mathrm{n}=131$ \\
\hline \multicolumn{2}{|c|}{ Possui tatuagem } \\
\hline Sim & $94(71,8)$ \\
\hline \multicolumn{2}{|c|}{ Uso de preservativo } \\
\hline Não & $90(87,4)$ \\
\hline Sim & $13(12,6)$ \\
\hline \multicolumn{2}{|c|}{ Tem conhecimento sobre sífilis } \\
\hline Não & $82(62,6)$ \\
\hline \multicolumn{2}{|l|}{ Teste rápido } \\
\hline Negativo & $116(88,5)$ \\
\hline \multicolumn{2}{|c|}{ VDRL } \\
\hline Negativo & $120(91,6)$ \\
\hline \multicolumn{2}{|c|}{ Titulação do VDRL } \\
\hline $1 / 2$ & $6(54,5)$ \\
\hline $1 / 8$ & $3(27,3)$ \\
\hline $1 / 16$ & $1(9,1)$ \\
\hline $1 / 32$ & $1(9,1)$ \\
\hline Negativo & 120 \\
\hline
\end{tabular}

$\mathrm{AIQ}=$ Amplitude interquartil. $\mathrm{DP}=$ desvio padrão.

*Valor obtido após aplicação do teste U de Mann Whitney.

**Valor obtido após aplicação do teste de razão de verossimilhança.

***Valor obtido após aplicação do teste Qui-quadrado de Pearson.

bValor estatisticamente significativo após análise de resíduo

Para iniciar a pesquisa foi utilizado o teste rápido de sífilis como triagem no estudo. Os resultados negativos do teste rápido já descartaram a 


\section{PRÁTICAS E SABERES EM

maioria dos reeducandos. Assim, a tabela 3 mostra três variáveis que foram confrontadas no estudo e seus respectivos resultados.

Tabela 3 - Variáveis cruzadas com o resultado dos testes rápido.

\begin{tabular}{|c|c|c|c|}
\hline \multirow{3}{*}{ Variáveis } & \multicolumn{2}{|c|}{ Teste rápido Mediana $\left(\mathrm{AIQ}^{\star}\right), \mathbf{n}(\%)$} & \multirow{3}{*}{ Valor-p } \\
\hline & Positivo & Negativo & \\
\hline & $n=15$ & $n=116$ & \\
\hline Idade (anos) & $33,87 \pm 10,67$ & $29,97 \pm 9,57$ & $0,175^{*}$ \\
\hline Até 30 anos & $8(53,3 \%)$ & $70(60,3)$ & $0,381^{* *}$ \\
\hline Entre 30 e 45 anos & $4(26,7)$ & $37(31,9)$ & \\
\hline Mais de 45 anos & $3(20,0)$ & $9(7,8)$ & \\
\hline $\begin{array}{c}\begin{array}{c}\text { Período preso } \\
\text { (anos) }\end{array} \\
\end{array}$ & $2,00(0,37-3,62)$ & $1,00(0,46-2,04)$ & $0,424^{*}$ \\
\hline \multicolumn{4}{|c|}{ Sexo } \\
\hline Masculino & $6(40,0)$ & $79(68,1)^{b}$ & $0,032^{* * *}$ \\
\hline Feminino & $9(60,0)^{\mathrm{b}}$ & $37(31,9)$ & \\
\hline
\end{tabular}

AIQ $=$ Amplitude interquartil. $\mathrm{DP}=$ desvio padrão.

*Valor obtido após aplicação do teste U de Mann Whitney.

**Valor obtido após aplicação do teste de razão de verossimilhança.

***Valor obtido após aplicação do teste Qui-quadrado de Pearson.

bValor estatisticamente significativo após análise de resíduos

A tabela 4 apresenta os resultados das variáveis analisadas na pesquisa dos VDRL positivo. A idade que mais prevaleceu na estatística foi reeducandos jovens, com período de reclusão de 2 (dois) anos e com escolaridade de ensino fundamental. A maior parte desses jovens possui o conhecimento da sífilis, mas não fazem o uso de preservativos nas visitas íntimas. 
Tabela 4 - Teste de VDRL positivo, negativo e suas variáveis.

\begin{tabular}{|c|c|c|c|}
\hline \multirow[t]{2}{*}{ Variáveis } & \multicolumn{2}{|c|}{ Mediana (AIQ) ou média \pm DP,n(\%) } & \multirow{2}{*}{ Valor-p } \\
\hline & Positivo $n=11$ & Negativo $n=120$ & \\
\hline Idade (anos) & $30,64 \pm 10,22$ & $30,75 \pm 9,45$ & $0,937^{\star}$ \\
\hline Até 30 anos & $8(72,7)$ & $70(58,3)$ & $0,487^{* *}$ \\
\hline Entre 30 e 45 anos & $2(18,2)$ & $39(32,5)$ & \\
\hline Mais de 45 anos & $1(9,1)$ & $11(9,2)$ & \\
\hline Período preso (anos) & $\begin{array}{c}2,00(0,33- \\
3,87)\end{array}$ & $1,00(0,46-2,12)$ & $0,485^{*}$ \\
\hline \multicolumn{4}{|c|}{ Sexo } \\
\hline Masculino & $4(36,4)$ & $81(67,5)^{b}$ & $0,050^{* * *}$ \\
\hline Feminino & $7(63,6)^{\mathrm{b}}$ & $39(32,5)$ & \\
\hline \multicolumn{4}{|c|}{ Estado } \\
\hline Sul & $10(90,9)$ & $115(95,8)$ & $0,653^{* *}$ \\
\hline Sudeste & $1(9,1)$ & $4(3,3)$ & \\
\hline Nordeste & $0(0,0)$ & $1(0,8)$ & \\
\hline \multicolumn{4}{|c|}{ Raça } \\
\hline Branco & $9(81,8)$ & $73(60,8)$ & $0,518^{* *}$ \\
\hline Pardo & $1(9,1)$ & $28(23,3)$ & \\
\hline Preto & $1(9,1)$ & $18(15,0)$ & \\
\hline Amarelo & $0(0,0)$ & $1(0,8)$ & \\
\hline \multicolumn{4}{|c|}{ Escolaridade } \\
\hline Ensino fundamental & $8(72,7)$ & $101(84,2)$ & $0,544^{\star *}$ \\
\hline Ensino médio & $3(27,3)$ & $15(12,5)$ & \\
\hline Ensino superior & $0(0,0)$ & $4(3,4)$ & \\
\hline \multicolumn{4}{|c|}{ Estado civil } \\
\hline Solteiro (a) & $7(63,6)$ & $57(47,5)$ & 0,479 ** \\
\hline União estável & $2(18,2)$ & $26(21,7)$ & \\
\hline Divorciado (a) & $1(9,1)$ & $3(2,5)$ & \\
\hline Viúvo (a) & $0(0,0)$ & $2(1,7)$ & \\
\hline
\end{tabular}

\section{Renda}




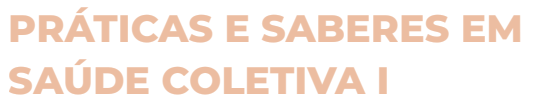

\begin{tabular}{c|c|c|c}
\hline Variáveis & \multicolumn{2}{|c|}{ Mediana (AIQ) ou média \pm DP,n(\%) } & \multirow{2}{*}{ Valor-p } \\
\cline { 1 - 2 } $\begin{array}{c}\text { Menor que 1 } \\
\text { salário-mínimo }\end{array}$ & $3(27,3)$ & $10(8,3)$ & \\
\hline $\begin{array}{c}\text { Entre 1 e 2 salári- } \\
\text { os-mínimos }\end{array}$ & $6(54,5)$ & $66(55,0)$ & \\
\hline $\begin{array}{c}\text { Entre 2 e 3 } \\
\text { salários-mínimos }\end{array}$ & $0(0,0)$ & $27(22,5)$ & \\
\hline $\begin{array}{c}\text { Entre 3 e 4 salári- } \\
\text { os-mínimos }\end{array}$ & $0(0,0)$ & $2(1,7)$ & \\
\hline
\end{tabular}

Maior que 4 salários-mínimos

\begin{tabular}{c|l|l|l}
\hline \multicolumn{5}{|c}{ Possui tatuagem } \\
\hline Sim & $7(63,6)$ & $87(72,5)$ & $0,504^{* * *}$ \\
\hline Não & $4(36,4)$ & $33(27,5)$ & \\
\hline
\end{tabular}

Uso de preservativo

\begin{tabular}{c|c|c|c}
\hline Não & $5(45,5)$ & $85(70,8)$ & $0,247^{* *}$ \\
\hline Sim & $2(18,2)$ & $11(9,2)$ & \\
\hline $\begin{array}{c}\text { Não recebe visita } \\
\text { íntima }\end{array}$ & $4(36,4)$ & $24(20,0)$ & \\
\hline
\end{tabular}

Tem conhecimento sobre sífilis

\begin{tabular}{c|l|l|l}
\hline Não & $5(45,5)$ & $77(64,2)$ & $0,329^{* * *}$ \\
\hline Sim & $6(54,5)$ & $43(35,8)$ & \\
\hline
\end{tabular}

$\mathrm{AIQ}=$ Amplitude interquartil. $\mathrm{DP}=$ desvio padrão.

*Valor obtido após aplicação do teste U de Mann Whitney.

${ }^{*}$ Valor obtido após aplicação do teste de razão de verossimilhança.

***Valor obtido após aplicação do teste exato de Fisher.

bValor estatisticamente significativo após análise de resíduo.

Atualmente, a pesquisa para sífilis é realizada combinando testes específicos e não específicos. A maioria dos autores utilizam o VDRL ou o RPR e o FTA-ABS ou o ELISA. Muitos laboratórios têm optado pelo VDRL 
e o ELISA por serem de fácil execução. Entre os testes não específicos, temos o VDRL e o teste imunocromatográfico, onde ambos são testes qualitativos, ambos de baixo custo, que ficam positivos entre as segundas e quartas semanas após aparecimento do cancro de inoculação e apresentando títulos mais elevados nas formas secundárias, recente latente e tardia. Por serem qualitativos e pela tendência de se tornarem negativos entre 6 (seis) e 12 (doze) meses, são os mais indicados para acompanhamento pós-terapêutico da doença. São testes não específicos, pois detectam anticorpos antilipídicos que surgem tanto na sífilis como em outras doenças (FRAMIL; NADAL, 2007).

Não foi obtido nenhum resultado positivo em reeducandas grávidas. Isto é, nenhuma apresentou o anticorpo para sífilis no teste rápido, o qual foi executada em todas as 6 reeducandas presentes no momento da pesquisa.

$\mathrm{O}$ teste rápido executado nos reeducandos foram identificadas 15 reeducandos positivos e 116 negativos. O teste não-treponêmico VDRL analisou essas 15 amostras positivas e positivou para 11 reeducandos.

Alguns reeducandos acrescentaram na pesquisa que já haviam sido portadores da sífilis anteriormente e que o tratamento tinha sido executado corretamente.

A prevalência no estudo de titulações baixas, segundo Framil e Nadal (2007), podem ser permanentes, como no lúpus eritematoso sistêmico, na síndrome antifosfolipídica e outras colagenoses, na hepatite crônica e no uso abusivo de drogas ilícitas injetáveis, na hanseníase, na malária, na mononucleose, na leptospirose ou podem ser temporários em algumas infecções, vacinações, medicamentos e transfusões de hemoderivados.

Conforme a citação acima de Framil e Nadal, verifica-se que uma reeducanda relatou que é portadora de lúpus, sendo que o VDRL da mesma foi apresentado como positivo e com sua titulação baixa. Assim, relatou que não tem relação sexual há anos, pois provavelmente a doença autoimune que a reeducanda apresenta interferiu no resultado do VDRL.

A média de idade que apresentou o teste de VDRL positivo foi de 30,64 anos. A maior prevalência de sífilis encontrada no estudo, entre jovens 
com idade entre 18 e 30 anos, com um período médio de reclusão de 2 anos, foi em mulheres reclusas.

Segundo o trabalho de Canazaro; Argimon (2010), foram estatisticamente associados à sorologia positiva para sífilis a maior média de idade, maior número de filhos, menos anos de estudo, ser interna na unidade prisional feminina, não selecionar seus parceiros e usar drogas antes das relações sexuais. Esses resultados coadunam com a literatura que aponta o sexo feminino como sendo de maior risco para contrair a sífilis e outras DST.

Segundo o boletim epidemiológico de sífilis (2017) a maior parte das pessoas notificadas foram brancas $(38,5 \%)$, seguidas de $33,1 \%$ de pessoas pardas e 9,3\% de pessoas pretas.

Tais resultados demonstram similaridades com estudos realizados em internos do sistema prisional de Teresina. Segundo Oliveira e Araújo (2014), a maior parcela possui escolaridade compatível com até oito anos de estudo (66\%). No tocante à renda, a expressiva maioria tem renda pessoal e familiar de até $\mathrm{R} \$ 720,00$, respectivamente $57,5 \%$, isso reflete na taxa de desemprego que o Nordeste sofreu em 2004, segundo dados do (IBGE, 2004), que chegou a atingir 9,3\% da população local.

A pesquisa identificou que 63,6 \% dos jovens são solteiros, e que $45,5 \%$ não fazem o uso de preservativos em visitas intimas, mas os reeducandos desta pesquisa tem o conhecimento sobre sífilis. Corroborando com os resultados de Araújo Filho e Feitosa (2012), onde 60,3\% afirmaram não manter relacionamento estável e 62,2\% não sabem como se dá a transmissão da sífilis.

Segundo o estudo de Negreiros, Vieira (2017) em um estudo de privados de liberdade, no qual se refere à história penal, a maior parte dos reeducandos são procedentes do estado de Rondônia, com pena total igual ou acima de 7 anos e reclusos há menos de 3 anos. Os fatores de risco mais prevalentes são: presença de tatuagem, tabagismo e etilismo. Colacionado com os nossos resultados, verificou-se que os reeducandos que são da região Sul do País possui a maior prevalência de sífilis, sendo, possivelmente, com mais incidência na Penitenciária Feminina e no Presídio Regional de Criciúma-SC. 
Sendo assim, se faz importante verificar que em cada estudo realizado, há uma prevalência diferente, devido muito ao fato de os estudos terem sido realizados em regiões distintas do País.

\section{CONCLUSÃO}

Diante do exposto, foi possível concluir a existência de associação entre o sexo feminino, VDRL positivo e teste rápido positivo. Ainda, existe um maior número de homens com VDRL e teste rápido negativo.

Assim, a sífilis dentro da Penitenciária Feminina e do Presídio Regional de Criciúma-SC acomete mais os jovens, entre 18 e 30 anos.

Diante dos objetivos, foi avaliada a prevalência de Treponema pallidum com relação às diferentes faixas etárias, onde foram encontrados reeducandos com idade mínima de 18 anos e máxima de 54 anos.

Nesse seguimento, obteve-se titulações positivas de reeducandos através do teste não-treponêmico para sífilis, o VDRL. Com titulações de 1:2, 1:8, 1:16 e 1:32. Logo, os resultados obtidos foi de 11 reeducandos com titulações positivas e 120 titulações negativas. Além do mais, foi associado o tempo que os reeducandos estão reclusos, concluído com o tempo médio de 2 anos.

Para execução de trabalhos futuros, sugere-se uma reunião com enfermeiros responsáveis pelo setor, agentes penitenciários e com o diretor geral de cada unidade. Assim, pode-se estabelecer dias de coleta e quantidade mínima por dia, a fim de que sejam realizados os procedimentos com organização dentro da unidade, com o intuito de receber estudantes da área da saúde. Acredita-se que, assim, a equipe do sistema prisional conseguiria entender o real sentido da pesquisa, bem como quão importante e benéfica é para a unidade prisional. Em consequência poderão ser levantados novos números e com resultados ainda mais fidedignos. 


\section{REFERÊNCIAS}

AVELLEIRA, João Carlos Regazzi; BOTTINO, Giuliana. Sífilis: Diagnóstico, tratamento e controle. Educação Médica Continuada, Rio de Janeiro, n. ??, p. 111-126, 2006.

AGNOLO, C. M. D; BELENTANI, L. M; JARDIM, A. P. S; CARVALHO, M. D. $\mathrm{B}$; PELLOSO, S. M. Perfil de mulheres privadas de liberdade no interior do Paraná. Rev. baiana saúde pública [Internet]. 2013,37(4):820-34. Disponível em: http://inseer.ibict.br/rbsp/index.php/rbsp/article/view/617.

BELDA JR., Walter; SHIRATSU, Ricardo; PINTO, Valdir. Abordagem nas doenças sexualmente transmissíveis. An Bras Dermatol. 2009; 84(2):151-59.

BLENCOWE, W; HANNAH, Cousens S.; KAMB, M.; BERMAN, S; LAEWN, J. E. Lives Saved Tool supplement detection and treatment of syphilis in pregnancy to reduce syphilis related stillbirths and neonatal mortality. BMC Public Health (Suppl 3): S9, 2011.

BIOCLIN. VDRL Pronto para uso. Disponível em: <http://www.bioclin. com.br/sitebioclin/wordpress/wpcontent/uploads/arquivos/instrucoes/ INSTRUCOES_VDRL.pdf>. Acesso em: 12 nov. 2015.

BRASIL. INFOPEN. (Org.). Levantamento Nacional. de Informações Penitenciárias Infopen - junho de 2014. Brasília, v. 0, n. 0, p. 1-147, jun. 2014. Disponível em: file://C:/Users/PATRINY/Desktop/relatoriodepen-versaoweb.pdf. Acesso em: 19 maio 2017.

CARLSON, J. A.; DABIRI, G.; CRIBER, B.; SELL, S. The immunopathobiology of syphilis: the manifestations and course of syphilis are determined by the level of delayed-type hypersensitivity. Am J Dermatopathol. 2011 COELHO H. C; PASSOS, A. D. C. Low prevalence of syphilis in Brazilian inmates. Braz Infect Dis 15(1):94-95, 2011.

CONTRERAS, Eduardo; ZULUAGA, Sandra Ximena; O CAMPO, Vanessa. Sífilis: um grande imitador. Infectio, Bogotá, n. , p. 1-11, 2 abr. 2008. 
GARAYCOCHEA, M. del C.; PINO, R.; CHÁVEZ, I., PORTILLA, J. L.; MIRAVAL, M. L.; ARGUEDAS, E. Infecciones de transmisión sexual en mujeres de un estabelecimiento penitenciario de Lima, Perú. Rev Peru Med Exp Salud Publica [Internet]. 2013. Disponível em: <http://www.scielo.org.pe/ scielo >. Acesso em: xx xxxx xxxx.

GRANGE, P. A. L; GRESSIER, P. L; DION, D.; FARHI, N.; BENHADDOU, P; GERHARDT, J. P.; MORINI, J.; DELEUZE, C.; PANTOJA, A.; BIANCHI, F; LASSAU, AVRIL, M. F.; JANIER, M.; DUPIN, N. Evaluation of a PCR Test for Detection of Treponema pallidum in Swabs and Blood Journal of Clinical Microbiology, p. 546-552, 2012.

LAFOND R. E; LUKEHART, S. A. Biological basis for syphilis. Clin Microbiol Rev 19: 29-49, 2006.

MEDRONHO, Roberto. A. Epidemiologia. Rio de Janeiro. Atheneu, 2. ed., 2008.

NICOLAU, A. I. O; RIBEIRO, S. G; LESSA, P. R. A; MONTE, A. S; FERREIRA, R. C. N; PINHEIRO, A. K. B. Retrato da realidade socioeconômica e sexual de mulheres presidiárias. Acta Paul Enferm [Internet]. 2012. Disponível em: <http://dx.doi.org/10.1590/S0103-21002012000300011>.

SANTA CATARINA. DIVE. (ed.). Sífilis. Florianópolis, v. 0, n. 0, p. 1-1, maio 2017. Disponível em: <http://www.dive.sc.gov.br/sifilis/>. Acesso em: 17 maio 2017.

SINGH A. E.; ROMANOWSKI, B. Syphilis: review with emphasis on clinical, epidemiologic, and some biologic features. Clin Microbiol Rev 12: 187-209, 1999.

TIPPLE, Craig; MARIAM, O. F; HANNA, H. S.; DANIEL, J.; GOLDMEIER, D.; MCCLURE, M. O.; TAYLOR, G. P. Getting the measure of syphilis: qPCR to better understand early infection Sex Trans Infect, n. 87, p. 479 e 485, 2011.

WHO. World Health Organization. 2012. Disponível em: <http://www.who. int/en>. Acesso em: xxxxxxx xxxxxxxxxxx xxxxxxxxxxx. 
FRAMIL, Valéria Maria de Souza; NADAL, Sidney Roberto. Interpretação das Reações Sorológicas para Diagnóstico e Seguimento Pós-Terapêutico da Sífilis. Scielo, São Paulo, v. 1, n. 1, p. 479-482, 12 abr. 2007. Disponível em: <http://www.scielo.br/pdf/rbc/v27n4/18.pdf>. Acesso em: 23 maio 2018.

BRASIL. Constituição (1975). Portaria n. 204, de 17 de fevereiro de 2016. O Ministro de Estado da Saúde, interino, no uso das atribuições que lhe conferem os incisos I e II do parágrafo único do art. 87 da Constituição. Brasília, Rio Grande do Sul: Governo.

SILVA, Geraedson Aristides da; OLIVEIRA, Cilmery Marly Gabriel de. $O$ registro das doenças de notificação compulsória: a participação dos profissionais da saúde e da comunidade. Revi, Maceió, v. 3, n. 4, p.1-6, 12 abr. 2014. Disponível em: <file://C:/Users/PATRINY/Downloads/4578-23778-1PB.pdf>. Acesso em: 23 fev. 2018.

ARAUJO, Telma Maria Evangelista de; ARAUJO FILHO, Augusto Cezar Antunes de; FEITOSA, Karla Vivianne Araújo. Prevalência de sífilis em mulheres do sistema prisional de uma capital do nordeste brasileiro. 2012. $11 \mathrm{f}$. Tese (Doutorado) - Curso de Enfermagem, Universidade Federal do Piauí (UFPI), Piauí, 2014.

OLIVEIRA, Elane Magalhães; ARAÚJO, Telma Maria Evangelista de. Prevalência da sífilis em internos do sistema prisional de Teresina. 2014. $3 \mathrm{f}$. Tese (Doutorado) - Curso de Enfermagem, Universidade Federal do Piauí, Piauí, 2014.

DIRETRIZES PARA CONTROLE DE SÍFILIS CONGÊNITA. Brasília: Dario Noleto, 2005.

BIOCLIN. SífilisBio: INSTRUÇÕES DE USO. Belo Horizonte: Bioclin, 2017. Disponível em: <https://www.bioclin.com.br/sitebioclin/wordpress/wpcontent/uploads/arquivos/instrucoes/INSTRUCOES_SIFILIS.pdf $>$. Acesso em: 30 maio 2018. 
BOLETIM EPIDEMIOLOFICO: Sífilis 2017. Brasília: Secretaria de Vigilância em Saúde - Ministério da Saúde, 2017

NEGREIROS, Daiany Elen Holanda; VIEIRA, Deusilene Souza. Prevalência de hepatites b, c, sífilis e hiv em privados de liberdade. 2017. 10 f. Tese (Doutorado) - Curso de Mestrado em Saúde da Família, Uninovafapi, Porto Velho, Rondônia, 2016.

CANAZARO, Daniela; ARGIMON, Irani Iracema de Lima. Características, sintomas depressivos e fatores associados em mulheres encarceradas no Estado do Rio Grande do Sul, Brasil. 2010. 11 f. Tese (Doutorado) - Pontifícia Universidade Católica do Rio Grande do Sul, Porto Alegre, Brasil. Rio de Janeiro, 2009. 